\title{
Efficient Exercise Volume Analysis through Number of Repetitions and EMG Response of Agonist Muscle During the Bench Press
}

Ki Hong Kim

Department of Recreation and Leisure Sports, Dankook University, Cheonan, Korea
Received November 16, 2021

Accepted December 22, 2021

\footnotetext{
Correspondence

Ki Hong Kim

Department of Recreation and Leisure Sports, Dankook University, 119 Dandae-ro, Dongnamgu, Cheonan 31116, Korea

Tel.: +82-41-550-3812

Fax: +82-41-559-7730

E-mail: bodykimahanmail.net

(C) Korean Society for Laser Medicine and Surgery

(c) This is an open access article distributed under the terms of the Creative Commons Attribution NonCommercial License (http://creativecommons.org/ licenses/by-nc/4.0) which permits unrestricted noncommercial use, distribution, and reproduction in any medium, provided the original work is properly cited.
}

\begin{abstract}
Background and Objectives
In designing a resistance exercise program, intensity, rest, and exercise volume are important. Many studies have been conducted to find the most suitable resistance exercise program incorporating the above, and in particular, many prior studies have been conducted on intensity. This study attempted to determine the effective volume of exercise by analyzing the number of repetitions performed at intensities of $65 \%$ onerepetition maximum (1RM) and $75 \% 1 \mathrm{RM}$ during the bench press exercise, and the electromyography (EMG) response of the agonist muscle.
\end{abstract}

\section{Materials and Methods}

Eight males in their 20s were selected as study subjects and they performed five sets of bench presses at two levels of intensity $165 \% 1 \mathrm{RM}$, $75 \% 1 \mathrm{RM})$. The following results were obtained by measuring the number of repetitions and the EMG response according to the exercise intensity and sets during the workout.

\section{Results}

First, the number of repetitions showed a sharp drop from the first set to the third set at $65 \% 1 \mathrm{RM}$ intensity and showed no change in the fourth and fifth sets. At 75\% 1RM intensity, the intensity of hypertrophy showed a gradual decrease from the first set to the fifth set. Second, at 75\% 1RM exercise intensity, the pectoralis major, anterior deltoid and triceps brachii showed high muscle activity, and the activity of the anterior deltoid continued to increase from the first set to the fourth set at $65 \%$ 1RM intensity, and from the first set to the fifth set at 75\% 1RM.

\section{Conclusion}

It was found that during the bench press exercise, three minutes of rest at 75\% 1RM intensity, five sets of five sets, one minute rest at $65 \% 1 \mathrm{RM}$ intensity, and three sets of the exercise were effective.

\section{Key words}

Bench press; Exercise set; Number of repetition; Electromyography 


\section{INTRODUCTION}

Resistance exercise is a training that stimulates the neuromuscular by using a weight load, and improves muscle functions such as strength, hypertrophy, and endurance. It is also used to improve the performance of athletes and to prevent injuries. ${ }^{1}$ On the other hand, if the load or amount of exercise is excessive, the effect is halved and the risk of exercise damage increases ${ }^{2}$ and causes chronic fatigue. ${ }^{3}$ In addition, since it is not helpful for conditioning and improving performance, the American Association of Sports Medicine recommends the application of a resistance exercise program based on scientific data suitable for the exercise target or exercise purpose. ${ }^{4}$

During resistance exercise, the effects and results differ according to the intensity of the exercise load, the number of repetitions, the number of sets, and the rest time between sets. ${ }^{5}$ Here, the intensity of the exercise load and the number of repetitions are set based on the RM (Repetition Maximum), which refers to the maximum weight one can lift once, and individual records are different. ${ }^{6}$ The maximum number of repetitions means the number of continuous motions that can perform a certain weight, and the RM value is applied differently depending on the purpose. ${ }^{7}$ Garhammer and Takano, ${ }^{8}$ Fleck and Kraemer ${ }^{9}$ found that, in general, the intensity of exercise according to purpose is greater than 85\%1RM for maximum muscle strength, 67-85\%1RM for hypertrophy, and less than 67\%1RM for muscular endurance.

In general, resistance exercise consists of several sets, and as the exercise performance is continued, the accumulated muscle fatigue leads to a decrease in the exerted strength and causes a set to failure, thereby reducing the amount of exercise. ${ }^{10}$ Regarding the optimal set for each exercise intensity, there is still disagreement among researchers. Peterson et al. ${ }^{11}$ reported that when the effect size for each set was analyzed during resistance exercise, a significant effect appeared in 4-8 sets, and Krieger ${ }^{12}$ reported that the effect size of resistance exercise with hypertrophy intensity was from 4-6 sets was said to be large. Also, Wernbom et al. ${ }^{13}$ showed that 4-6 sets showed the largest cross-sectional area during training for the purpose of muscle hypertrophy, and 3-3.5 sets and 9 sets showed little effect. Therefore, it is necessary to investigate the effective amount of exercise.

The Bench Press is an action that pushes up the barbell with both hands while lying on a flat bench. It is an effective multi-joint exercise for developing Pectoralis major and triceps brachii by simultaneously generating horizon- tal adduction of the shoulder and extension of the elbow. ${ }^{14}$

When the small muscle group becomes fatigued, the large muscle group's exercise capacity decreases ${ }^{10}$, and the exhaustion exercise method, which performs as many repetitions as possible until a certain load temporarily fails, requires more motor units ${ }^{9}$. Sequential motor unit mobilization of slow twich muscle (ST) and fast twich muscle (FT) fibers ${ }^{6}$ was used to maintain a constant force even after fatigue started after pre-exhaustion exercise, and muscle fatigue caused by this, was As a result, it leads to a decrease in tension, leading to a decrease in exercise performance. ${ }^{15}$

In this study, the same subjects were classified into a low-intensity maximum repetition (65\% 1RM, 5 sets, 1 minute rest) group and a high-intensity maximum repetition (75\% 1RM, 5 sets, 3 minutes rest) group, and then the effective amount of exercise for each exercise intensity was investigated by analyzing the number of repetitions, and the mobilization patterns of pectoralis major, the triceps brachii, and anterior deltoid muscles.

\section{MATERIALS AND METHODS}

\section{Subject}

The subjects of this study were males in their 20s with more than 6 months of resistance exercise experience who expressed their intention to participate voluntarily. Eight people who signed the written consent were selected while fully informed of the expected benefits and inherent risks and inconveniences. In accordance with the regulations of the institutional review board (IRB) based on the declaration of helsinki for the finally selected personnel, the purpose of the study, the contents and participation period of the study, risk factors, and the freedom to stop the experiment were explained, and then voluntary consent was obtained. The physical characteristics of the study subjects are shown in Table 1.

\section{Experimental procedure}

After the selection of subjects, the maximum muscle strength (1RM) of the bench press was measured two weeks before the experiment, and then the weights of $75 \% 1 \mathrm{RM}$ and $65 \% 1 \mathrm{RM}$ were measured by randomizing

Table 1. The characteristics of the subjects

\begin{tabular}{cccccc}
\hline $\mathrm{N}$ & $\begin{array}{c}\text { Age } \\
\text { (year) }\end{array}$ & $\begin{array}{c}\text { Weight } \\
(\mathrm{kg})\end{array}$ & $\begin{array}{c}\text { Height } \\
(\mathrm{cm})\end{array}$ & $\begin{array}{c}\text { Career } \\
\text { (year) }\end{array}$ & $\begin{array}{c}\text { Bench press } \\
1 \mathrm{RM}(\mathrm{kg})\end{array}$ \\
\hline 8 & $25.92 \pm 1.76$ & $78.00 \pm 3.34$ & $176.45 \pm 3.01$ & $2.71 \pm 1.12$ & $95.52 \pm 9.34$ \\
\hline
\end{tabular}


the subjects into two groups one week before. On the day of the experiment, the subject attached a surface electrode after performing warm-up exercises and performed 5 sets of maximum repetition bench press under a specified load.

\section{Bench press exercise}

The subject puts the soles of both feet on the floor, and attaches the hips, shoulders, and head to the bench. The starting position is completed when an assistant holds the bar with an overhand grip and lifts the barbell until the subject's arms are fully extended.

With the elbows fully extended, the subject bends his elbows at least $90^{\circ}$ and lowers the barbell toward his chest. At this point, he keeps the elbows close to his shoulders and in a straight line. Then, he raises the barbell again until all elbows are fully extended and repeats at a constant speed. He stops repeating when he slows down or stops at the sticking point.

\section{Set exercise intensity}

In order to determine the 75\% 1RM and 65\% 1RM weight of the bench press to be applied to the experiment, the maximum weight (1RM) of one repetition of the bench press was inspected 2 weeks before the experiment, and based on the 1RM measured 1 week ago, the $75 \% 1 \mathrm{RM}$ and $65 \% 1 \mathrm{RM}$ was measured. The measurement was applied according to the measurement environment after referring to the literature of national strength and conditioning association (NSCA). ${ }^{16}$

When measuring 1RM, the first set was set to a weight estimated to be repeated 3 to 5 times by warming up with a weight that can be repeated 5 to 10 times, and then increasing the weight load by $5-10 \mathrm{~kg}$ after resting for 1 minute. After that, a rest period of 2 minutes was provided, and the weight was increased by $5-10 \mathrm{~kg}$, set to a weight estimated to be able to be repeated 2-3 times, and then lifted, and a rest of 2-4 minutes was provided. Then, the weight of 5-10 kg was further increased to try $1 \mathrm{RM}$. When the bench press was successful, the weight was increased after a rest for 2-4 minutes, and when the bench press failed, the weight was reduced by $2.5-5 \mathrm{~kg}$ after a break of 2-4 minutes and then repeated to determine 1RM (Fig. 1). It was based on the number of times performed in the correct posture, and an assistant was placed to prevent the risk of injury during the measurement. Afterwards, the weights of $75 \% 1 \mathrm{RM}$ and $65 \% 1 \mathrm{RM}$ were measured by adjusting the weight according to the indirect measurement formula based on the pre-measured weight load of $1 \mathrm{RM}$. The average of $75 \% 1 \mathrm{RM}$ was $70.37 \mathrm{~kg}$, and the average of $65 \% 1 \mathrm{RM}$ was $60.99 \mathrm{~kg}$ of the study subjects.

$$
\begin{gathered}
1 R M=W 0+W 1 \\
\text { W0 = Weight that can bo contracted 7 8 repetitions } \\
\text { after sufficient warm up } \\
W 1=W 0 * 0.025 * R \\
R=\text { number of reptitions }
\end{gathered}
$$

\section{Electromyography measurement method}

An electromyography (EMG) machine (Korea, Laxtha) was used to investigate muscle activity during exercise, and the surface electrode was attached with reference to the study of Konrad ${ }^{17}$. In order to obtain high-quality EMG data, the hair of the outer skin layer was shaved using a razor before electrode attachment, and the skin surface was cleaned with alcohol.

Electromyography was measured in three muscles, the pectoralis major, anterior deltoid, and triceps brachii, which are the prime movers of the bench press, following the method of previous studies. When attaching the electrodes, two were attached each to the site $1 \mathrm{~cm}$ apart from the insertion site of the intramuscular electrode.

The electrode attachment location of the pectoralis

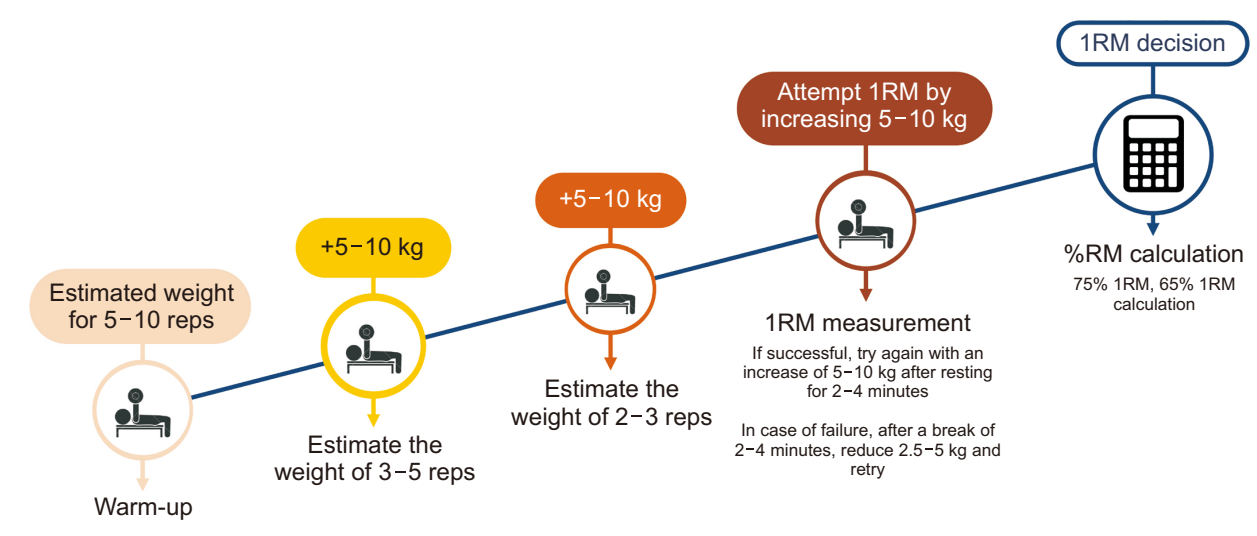

Fig. 1. 1RM measurement. 

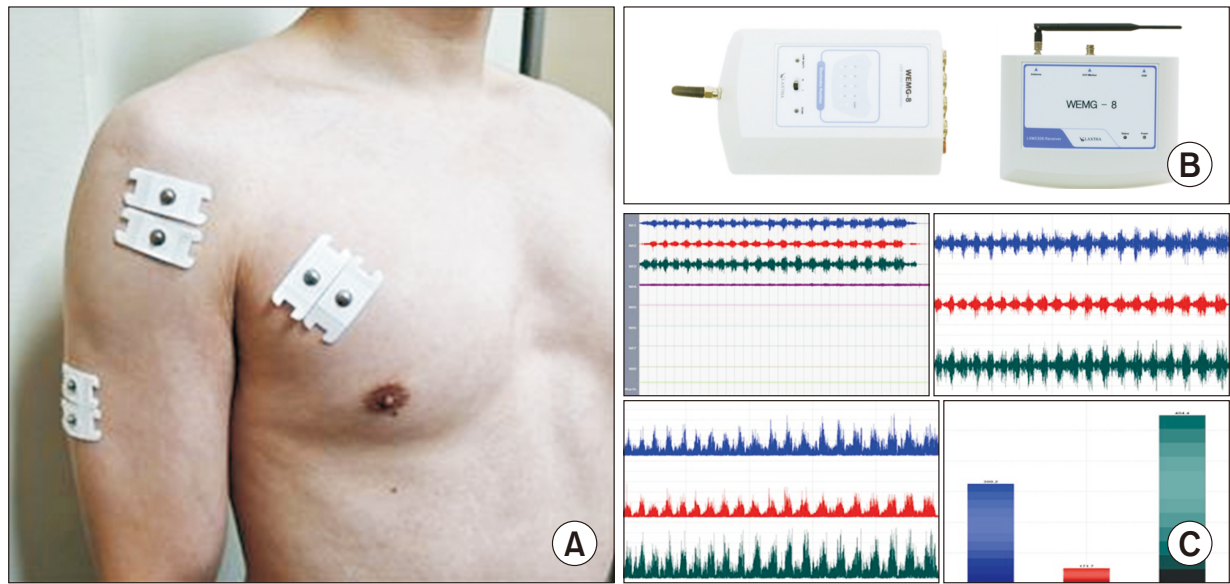

Fig. 2. Measurement and analysis of electromyography. (A) It shows the electrode attachment positions of pectoralis major, anterior deltoid, and triceps brachii. (B) EMG measurement system (C) Calculation of iEMG through the analysis of EMG raw data. Blue is pectoralis major, red is anterior deltoid, green is triceps brachii.

major muscle (Pectoralis major) was attached to the anterior axillary fold, the midpoint between the sternum and the anterior axilla in the supine position. Electrodes were attached to the anterior deltoid at a point 3 fingers wide from the front edge of the acromion. Triceps brachii-lateral head was attached to a point as far as 4 fingers wide from the posterior axillary fold, distal after the subject had their arms spread out in the Prone position. In addition, the wires connecting the electrodes and the electromyogram were arranged and fixed with tape, and then measured to minimize noise generation. It was monitored by designating the channel of the muscle at the electrode attachment site in the EMG program (Fig. 2).

\section{EMG signal analysis}

Telescan software (ver. 3.15, Laxtha) was used to observe muscle activity from the measured EMG raw data. To calculate the integral electromyogram (iEMG) by extracting the measured raw signal data for each exercise set, the $y$-axis value was set to 0 after offset control of the raw EMG signal. The range was set as $10-400 \mathrm{~Hz}$ for band pass FFT-filtering. After that, the integral was taken and the average was calculated.

\section{Statistical analysis}

For the data measured in this experiment, the mean and standard deviation of all variables were calculated using the IBM SPSS Statistics (ver 22.0) statistical program. To verify all dependent variables according to exercise intensity (2) and set (5), repeated measurement two-way ANOVA analysis was performed, and if significant differences occurred, Bonferroni post-hoc test was performed. All statistical significance levels were set to less than $\alpha$ $=.05$.

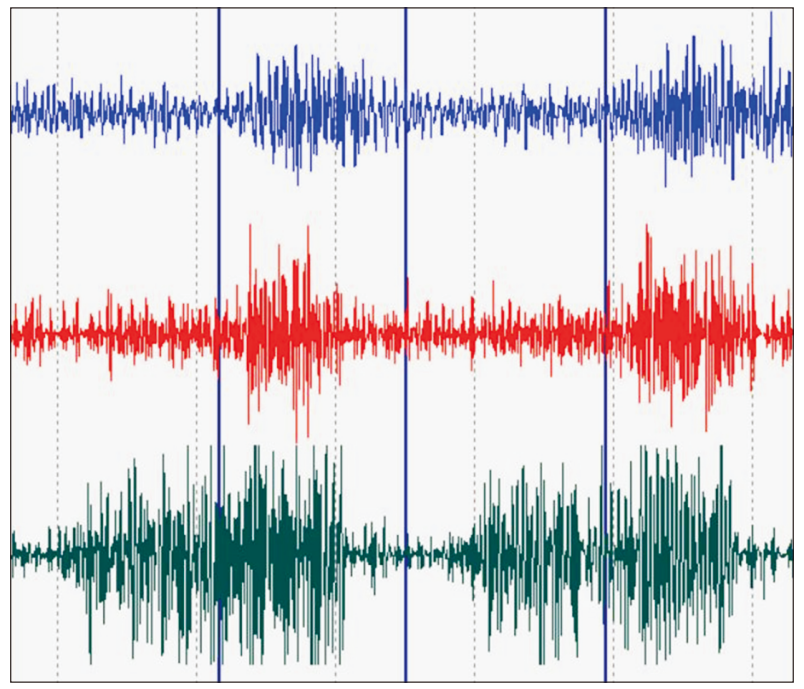

Fig. 3. Recruitment muscles during bench press exercise. Blue is pectoralis major, red is anterior deltoid, green is triceps brachii.

\section{RESULTS}

During bench press exercise, the sequence of muscle activity occurred in the order of triceps brachii, anterior deltoid, and pectorails major. The visualized EMG signal is shown in Fig. 3.

\section{Change in the number of repetitions according to exercise intensity during bench press}

There was a statistically significant difference in the number of repetitions according to exercise intensity during bench press, and 65\% 1RM intensity was high in all sets $(p<.001)$. There was also a significant difference in the number of repetitions according to the set, and in $75 \% 1 \mathrm{RM}$, it was significantly lowered from 2 sets to 4 sets $(p<.05, p<.001, p<.01)$. At 65\% 1RM, it decreased from 
2 sets to 5 sets $(p<.001)$. There was an interaction effect according to exercise intensity and set. The point of time when difference between the independent variable occurs can be observed through the interaction effect. The results of repeated measurement two-way ANOVA analysis and post-hoc for number of repetitions during bench press exercise are as shown in Table 2. The Change in number of repetitions is shown in Fig. 4.

\section{EMG response according to exercise intensity during bench press \\ iEMG changes in the pectoralis major muscle}

There was a statistically significant difference in iEMG

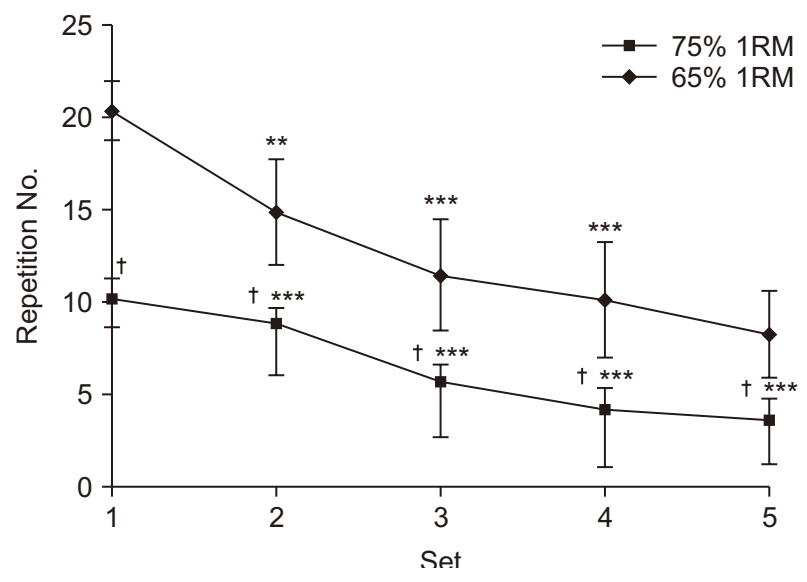

Fig. 4. Change in number of repetitions. ${ }^{\dagger} p<.01$, difference between intensity determined by Bonferroni post-hoc test. ${ }^{*} p<.01$, ${ }_{* * *} p<.001$, difference between set determined by Bonferroni posthoc test. of pectoralis major muscle according to exercise intensity, and 75\% 1RM intensity was high in all sets ( $p<.05)$. The results of repeated measurement two-way ANOVA analysis and post-hoc for iEMG of pectoralis major during bench press exercise are as shown in Table 3. iEMG changes in the pectoralis major muscle is shown in Fig. 5.

\section{iEMG changes in the triceps brachii muscle}

There was no statistically significant difference in triceps brachii muscle iEMG according to exercise intensity. The iEMG according to the set showed a significant difference. At 75\%1RM intensity, 5 set was significantly higher than 1 set $(p<.05)$. At $65 \% 1 \mathrm{RM}$ intensity, 3 set were significantly higher than 1 set and 5 set $(p<.05)$. The results of repeated measurement two-way ANOVA analysis and

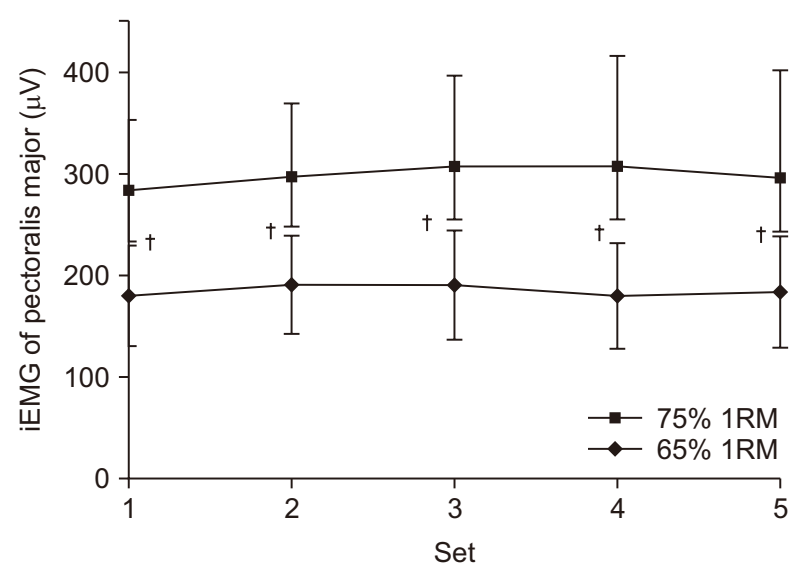

Fig. 5. iEMG changes in the pectoralis major muscle. ${ }^{\dagger} p<.05$, difference between intensity determined by Bonferroni post-hoc test.

Table 2. Change in number of repetitions according to exercise intensity during bench press

\begin{tabular}{|c|c|c|c|c|c|c|c|c|}
\hline & 1 set & 2 set & 3 set & 4 set & 5 set & & $F$ & $p$ \\
\hline $\begin{array}{l}75 \% 1 \mathrm{RM} \\
65 \% 1 \mathrm{RM}\end{array}$ & $\begin{array}{l}10.25 \pm 1.04 \\
20.38 \pm 1.60^{\dagger}\end{array}$ & $\begin{array}{c}8.88 \pm 0.83^{* *} \\
14.88 \pm 2.85^{\dagger_{* * *}}\end{array}$ & $\begin{array}{r}5.75 \pm 0.89^{* * *} \\
11.50 \pm 3.02^{1_{* * *}}\end{array}$ & $\begin{array}{c}4.25 \pm 1.16^{* * *} \\
10.13 \pm 3.14^{\dagger * * *}\end{array}$ & $\begin{array}{l}3.63 \pm 1.19 \\
8.25 \pm 2.38^{\dagger * * *}\end{array}$ & $\begin{array}{l}\text { Intensity } \\
\text { Set } \\
\text { (I) X (S) }\end{array}$ & $\begin{array}{r}53.561 \\
270.659 \\
20.854\end{array}$ & $\begin{array}{l}.000 \\
.000 \\
.000\end{array}$ \\
\hline
\end{tabular}

Values are means and SD.

${ }^{\dagger} p<.01$, difference between intensity determined by Bonferroni post-hoc test.

${ }^{* *} p<.01,{ }^{* * *} p<.001$, difference between set determined by Bonferroni post-hoc test.

Table 3. $\mathrm{iEMG}$ changes in the pectoralis major muscle

\begin{tabular}{|c|c|c|c|c|c|c|c|c|}
\hline & 1 set & 2 set & 3 set & 4 set & 5 set & & $\mathrm{F}$ & $p$ \\
\hline $75 \% 1 \mathrm{RM}$ & $283.00 \pm 69.91$ & $296.13 \pm 72.38$ & $307.56 \pm 87.53$ & $307.33 \pm 108.67$ & $296.54 \pm 104.00$ & Intensity & 11.56 & .011 \\
\hline $65 \% 1 \mathrm{RM}$ & $179.51 \pm 49.38^{*}$ & $190.71 \pm 48.16^{*}$ & $189.85 \pm 53.27^{*}$ & $179.69 \pm 52.53^{*}$ & $183.86 \pm 54.18^{*}$ & $\begin{array}{l}\text { Set } \\
\text { (I) X(S) }\end{array}$ & $\begin{array}{l}.633 \\
.361\end{array}$ & $\begin{array}{l}.526 \\
.698\end{array}$ \\
\hline
\end{tabular}

Values are means and SD. Greenhouse-Geisser.

${ }^{*} p<.05$, difference between intensity determined by Bonferroni post-hoc test. 
post-hoc for iEMG of triceps brachii during bench press exercise are as shown in Table 4. iEMG changes in the triceps brachii muscle is shown in Fig. 6 .

\section{iEMG changes in the anterior deltoid muscle}

There was no statistically significant difference in iEMG of the deltoid muscle according to the exercise intensity. The iEMG according to the set showed a significant difference, and in 75\% 1RM, it increased in 3 sets $(p<.05)$, and in $65 \% 1 \mathrm{RM}$, it increased in 2 sets $(p<.05)$. The results of repeated measurement two-way ANOVA analysis and post-hoc for iEMG of anterior deltoid during bench press exercise are as shown in Table 5. iEMG changes in the anterior deltoid muscle is shown in Fig. 7.

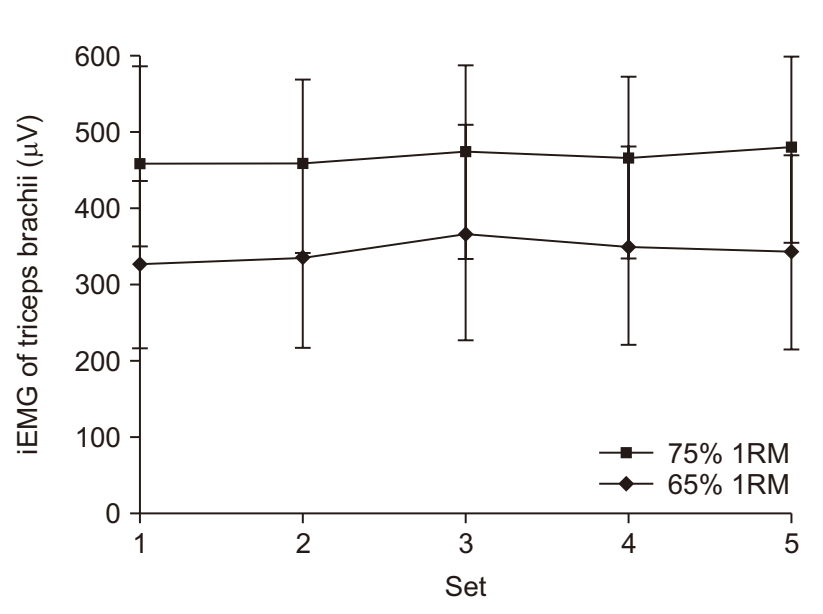

Fig. 6. iEMG changes in the triceps brachii muscle.

\section{DISCUSSION}

In designing a resistance exercise program, exercise load intensity, rest time between set, the number of repetitions, and the number of sets are very important. In fact, many scholars have researched to find a resistance exercise program suitable for the purpose, and in particular, many prior studies have been conducted on the rest period between set, exercise load intensity, and the number of repetitions. In this study, the same subjects were classified into a low-intensity maximum repetition $165 \%$ 1RM, 5 sets, 1 minute rest) group and a high-intensity maximum repetition (75\% 1RM, 5 sets, 3 minutes rest) group, and then the number of repetitions and the mobilization patterns of pectoralis major, the triceps brachii and anterior deltoid, pectoralis major were analyzed.

There was a statistically significant difference in the

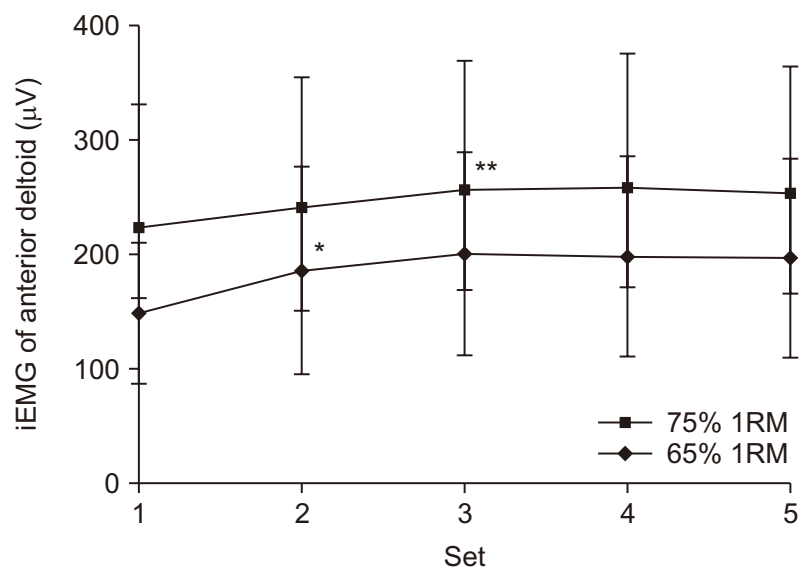

Fig. 7. iEMG changes in the anterior deltoid muscle. ${ }^{*} p<.05,{ }^{*} p<$ .01 difference between set determined by Bonferroni post-hoc test.

Table 4. iEMG changes in the triceps brachii muscle

\begin{tabular}{|c|c|c|c|c|c|c|c|c|}
\hline & 1 set & 2 set & 3 set & 4 set & 5 set & & $\mathrm{F}$ & $p$ \\
\hline $75 \% 1 \mathrm{RM}$ & $459.72 \pm 127.32$ & $459.64 \pm 109.05$ & $475.08 \pm 112.51$ & $466.56 \pm 105.02$ & $479.92 \pm 120.00$ & Intensity & 4.516 & .071 \\
\hline $65 \% 1 \mathrm{RM}$ & $326.71 \pm 110.08$ & $335.41 \pm 117.25$ & $367.97 \pm 141.03$ & $351.58 \pm 130.41$ & $342.66 \pm 125.27$ & Set & 3.224 & .027 \\
\hline & & & & & & (I) $X(S)$ & 1.612 & .199 \\
\hline
\end{tabular}

Values are means and SD.

Table 5. iEMG changes in the anterior deltoid muscle

\begin{tabular}{|c|c|c|c|c|c|c|c|c|}
\hline & 1 set & 2 set & 3 set & 4 set & 5 set & & $\mathrm{F}$ & $p$ \\
\hline $75 \% 1 \mathrm{RM}$ & $223.94 \pm 107.20$ & $241.93 \pm 113.34$ & $257.90 \pm 111.81^{* *}$ & $258.79 \pm 117.52$ & $254.11 \pm 110.59$ & Intensity & 2.175 & .184 \\
\hline $65 \% 1 \mathrm{RM}$ & $149.05 \pm 62.16$ & $186.56 \pm 90.02 *$ & $201.29 \pm 88.92$ & $199.03 \pm 87.74$ & $197.17 \pm 86.96$ & $\begin{array}{l}\text { Set } \\
\text { (I) X(S) }\end{array}$ & $\begin{array}{r}17.305 \\
.682\end{array}$ & $\begin{array}{l}.001 \\
.530\end{array}$ \\
\hline
\end{tabular}

Values are means and SD. Greenhouse-Geisser.

${ }^{*} p<.05,{ }^{*} p<.01$, difference between set determined by Bonferroni post-hoc test. 


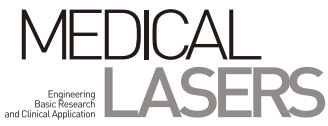

number of repetitions during bench press exercise according to exercise intensity, and the number of repetitions was higher in the 65\% 1RM exercise intensity condition than in the 75\% 1RM exercise intensity condition $(p<.001)$. There was also a significant difference in the number of repetitions according to the set, and it was significantly lowered to $1,2,3,4$, and 5 sets in the $65 \% 1 \mathrm{RM}$ exercise intensity condition ( $p<.001)$, and also in the 75\% $1 \mathrm{RM}$ exercise intensity condition. 1, 2, 3, 4, and 5 sets, the number of repetitions decreased significantly $(p<.001)$, There was also a significant difference in the interaction effect between exercise intensity and set $(p<.001)$.

As for the number of repetitions for the exercise intensity measured in this study, the 65\% 1RM exercise intensity condition would have mobilized FT fibers as the set progressed after mobilization of ST fibers compared to the $75 \% 1 \mathrm{RM}$ exercise intensity condition ${ }^{6}$, and for this reason, the number of repetitions between sets of the $75 \% 1 \mathrm{RM}$ exercise intensity condition showed a significant decrease in the number of repetitions from 1 set to 3 sets, and 4 and 5 sets showed a significant decrease in the number of repetitions between sets. It is thought to indicate the number of repetitions of the state. The number of repetitions between sets of 65\% 1RM exercise intensity condition decreased by half in 3 sets, which is consistent with NSCA ${ }^{16}$ asserting that the optimal number of sets of 60-65\%1RM exercise intensity condition is 2 to 3 sets. It is thought to indicate that the number of sets can be considered when planning a muscular endurance training program of resistance training.

In addition, the 75\% 1RM exercise intensity condition was because the exercise mobilized FT fibers was performed compared to the $65 \%$ 1RM exercise intensity condition. reported that a lot of muscle fatigue comes from performing relatively heavy weights first, which means that more motor units must be mobilized in order to exert or maintain strength after fatigue begins. ${ }^{18}$ The high number of repetitions of $65 \% 1 \mathrm{RM}$ compared to $75 \% 1 \mathrm{RM}$ is seemed to be expected because the lower the load, the higher the number of repetitions, and the lower the number of repetitions at the high load. ${ }^{7}$ In addition, the number of repetitions at $65 \% 1 \mathrm{RM}$ was $100 \%, 73 \%, 56 \%$, $50 \%, 40 \%$ compared to the first set, and the number of repetitions at $75 \% 1 \mathrm{RM}$ was $100 \%, 87 \%, 56 \%, 50 \%, 35 \%$ compared to the first set.

The rapid decrease in the number of repetitions at $65 \%$ $1 R M$ is judged to be insufficient for the replenishment time of ATP (adenosine triphosphate) and CP (creatine phosphate) due to the short rest time ${ }^{19}$. In this study, under the 65\% 1RM exercise intensity condition, the de- crease in the number of repetitions in sets $2,3,4$, and 5 compared to the number of repetitions in 1 set can be seen as a phenomenon of muscle fatigue of the prime mover during bench press. Also, considering that the rest period between sets was 3 minutes even under the $75 \%$ 1RM exercise intensity condition, the energy supplemented by using ATP and PC, which was sufficiently supplemented due to the rest period of 3 minutes between sets ${ }^{7}$ can be used so that the subject can perform the exercise up to the 5 set.

However the muscle fatigue of the prime mover appeared and the exercise performance was considered to have decreased.

Electromyography detects electrical signals that cause muscle contraction, ${ }^{17}$ and since the number of repetitions proceeds under the same load, the higher the number of motor units mobilized, the higher the value, ${ }^{9,20}$ used as an indicator of muscle activity. ${ }^{21}$

When examining the EMG response in the total number of repetitions during the 5 -set bench press according to the exercise intensity, the EMG response of the pectoralis major muscle showed a generally high tendency at 75\% 1RM. In addition, the activity of pectoralis major muscle by set showed a maximum in 2 sets of $65 \% 1 \mathrm{RM}$ and 3 sets of $75 \% 1 \mathrm{RM}$, and thereafter, there was a tendency to decrease gradually. On the other hand, the EMG response of the triceps brachii and anterior deltoid did not show any significant difference in exercise intensity, and the triceps brachii muscle showed the maximum in 5 sets at $75 \%$ $1 \mathrm{RM}$ and 3 sets at $75 \% 1 \mathrm{RM}$. The triceps anterior muscles showed the maximum in 3 sets regardless of the exercise intensity.

The mean electromyogram (mEMG) increases with the increase in fatigue according to the increase in load and exercise ${ }^{1}$, and as the relative strength increases during resistance exercise, the level of effort to continue the exercise increases. As additional motor unit synchronization occurs to compensate for the decreased contractile force of the tired motor unit with the increase in frequency ${ }^{22,23}$ along with the increase of action potential firing, the greater the number of motor units with maximal repetition. was mobilized. ${ }^{18}$

In particular, among all the sets, the maximum iEMG values tended to appear in the 3rd set, which was reported by González-Badillo et al. ${ }^{24}$, the lower iEMG after 3 sets means that fewer muscle fibers are recruited, ${ }^{25}$ After 3 sets, the amount of exercise reduced to half at all intensities is thought to be caused by muscle fatigue. In addition, at $65 \% 1 \mathrm{RM}$, the muscle activity of the anterior deltoid and triceps brachii was found to reach the maxi- 
mum in the middle of the entire set, and at 75\% 1RM, the maximum in the latter half of the entire set. At this time, the activity of the pectoralis major muscle decreased slightly, so at low intensity, preferential mobilization of ST fibers to perform a high amount of exercise occurred, and at high intensity, preferential expression of pectoralis major muscle with a high FT fiber ratio appeared and fatigue occurred. It is thought that the intervention of the anterior deltoid muscle to maintain performance was shown. ${ }^{6}$

\section{CONCLUSION}

The change in the number of repetitions during the exercise of 5 sets of bench press showed a sharp decrease from 1st to 3rd sets in the 65\% 1RM intensity bench press, but there was no change in 4 sets and 5 sets. In the muscle hypertrophy-type 75\% 1RM intensity bench press, it showed a gradual decrease from 1 st set to 5 th set. In the electromyographic response of the prime mover, the pectoralis major, anterior deltoid and triceps brachii showed high muscle activity at 75\%1RM exercise intensity. The anterior deltoid muscle continued to increase from 1 set to 4 sets at $65 \% 1 \mathrm{RM}$ intensity, and continued to increase from 1 set to 5 sets at 75\% 1 RM intensity.

It is thought that the anterior deltoid muscle was activated after muscle activation of the pectoralis major and triceps brachii during bench press exercise, and it is thought that the steady state and rapid decrease in the number of repetitions appeared at the time of high muscle activity of the anterior deltoid muscle.

As a result, it is considered that 5 sets of exercise are effective for 3 minutes of rest at 75\% 1RM (hypertrophy) during bench press exercise, and 3 sets of exercise with 1 minute of rest at 65\% 1RM (muscular endurance) are effective.

\section{CONFLICT OF INTEREST}

No potential conflict of interest relevant to this article was reported.

\section{FUNDING}

The present research was supported by the research fund of Dankook university in 2020.

\section{ORCID}

Ki Hong Kim, https://orcid.org/0000-0002-5614-1326

\section{REFERENCES}

1. Kraemer WJ, Ratamess NA. Fundamentals of resistance training: progression and exercise prescription. Med Sci Sports Exerc 2004;36:674-88.

2. Bodine SC, Stitt TN, Gonzalez M, Kline WO, Stover GL, Bauerlein $\mathrm{R}$, et al. Akt/mTOR pathway is a crucial regulator of skeletal muscle hypertrophy and can prevent muscle atrophy in vivo. Nat Cell Biol 2001;3:1014-9.

3. Kenney WL, Wilmore JH, Costill DL. Physiology of Sport and Exercise. Champaign: Human Kinetics; 2015.

4. Moore GE, Durstine JL, Painter PL. ACSM's Exercise Management for Persons with Chronic Diseases and Disabilities. Champaign: Human Kinetics; 2003.

5. Ratamess NA. ACSM's Foundations of Strength Training and Conditioning. Philadelphia: Lippincott Williams \& Wilkins; 2021.

6. O'Shea P. Quantum Strength \& Power Training: Gaining the Winning Edge. Corvallis: Patrick's Books; 1995.

7. Bompa TO, Buzzichelli C. Periodization: Theory and Methodology of Training. Champaign: Human Kinetics; 2018.

8. Garhammer J, Takano B. Training for weightlifting. In: Komi PV, editor. Strength and Power in Sport. Hoboken: John Wiley \& Sons, Inc.; 1992. p.357-69.

9. Fleck SJ, Kraemer WJ. Designing Resistance Training Programs. 4th ed. Champaign: Human Kinetics; 2014.

10. Kim KH. Effects of method and Intensity of Resistance Exercise on pectoralis major and triceps brachii iEMG, MEF, Repetition at 10RM Bench Press after single joint all out pre exercise. Asian J Kinesiol 2014;16:51-62.

11. Peterson MD, Rhea MR, Alvar BA. Maximizing strength development in athletes: a meta-analysis to determine the doseresponse relationship. J Strength Cond Res 2004;18:377-82.

12. Krieger JW. Single vs. multiple sets of resistance exercise for muscle hypertrophy: a meta-analysis. J Strength Cond Res 2010;24:1150-9.

13. Wernbom M, Augustsson J, Thomeé R. The influence of frequency, intensity, volume and mode of strength training on whole muscle cross-sectional area in humans. Sports Med 2007;37:225-64.

14. Evans N. Bodybuilding Anatomy. Champaign: Human Kinetics; 2015

15. Amann M, Dempsey JA. Locomotor muscle fatigue modifies central motor drive in healthy humans and imposes a limitation to exercise performance. J Physiol 2008;586:161-73.

16. Haff G, Triplett NT. Essentials of Strength Training and Conditioning. 4th ed. Champaign: Human Kinetics; 2016.

17. Konrad P. The ABC of EMG- A Practical Introduction to Kinesiological Electromyography. Noraxon INC.; 2005. p.30-5.

18. Mottram CJ, Jakobi JM, Semmler JG, Enoka RM. Motor-unit activity differs with load type during a fatiguing contraction. J 
Neurophysiol 2005;93:1381-92.

19. Powers SK, Howley ET, Cotter J, De Jonge XJ, Leicht A, Mundel T, et al. Exercise Physiology: Australia/New Zealand. New York: McGraw-Hill; 2014.

20. Taylor AD, Bronks R, Smith P, Humphries B. Myoelectric evidence of peripheral muscle fatigue during exercise in severe hypoxia: some references to $\mathrm{m}$. vastus lateralis myosin heavy chain composition. Eur J Appl Physiol Occup Physiol 1997;75:151-9.

21. Tillin NA, Pain MT, Folland JP. Short-term unilateral resistance training affects the agonist-antagonist but not the force-agonist activation relationship. Muscle Nerve 2011;43:375-84.

22. Wallace B, Janz J. Implications of motor unit activity on ballistic movement. Int J Sports Sci Coach 2009;4:285-92.

23. Del Vecchio A, Negro F, Holobar A, Casolo A, Folland JP, Felici $F$, et al. You are as fast as your motor neurons: speed of re- cruitment and maximal discharge of motor neurons determine the maximal rate of force development in humans. J Physiol 2019;597:2445-56.

24. González-Badillo JJ, Rodríguez-Rosell D, Sánchez-Medina L, Ribas J, López-López C, Mora-Custodio R, et al. Short-term recovery following resistance exercise leading or not to failure. Int J Sports Med 2016;37:295-304.

25. Linnamo V, Moritani T, Nicol C, Komi PV. Motor unit activation patterns during isometric, concentric and eccentric actions at different force levels. J Electromyogr Kinesiol 2003;13:93-101.

How to cite this article: Kim KH. Efficient exercise volume analysis through number of repetitions and EMG response of agonist muscle during the bench press. Med Lasers 2021; 10:220-228. https://doi.org/10.25289/ML.2021.10.4.220 